\title{
Continuous Multiple Prediction of Stream Data Based on Hierarchical Temporal Memory Network
}

\author{
Han Chang-yeong ${ }^{\dagger} \cdot$ Kim Sung-jin $^{++} \cdot$ Kang Hyun-syug ${ }^{+++}$
}

\begin{abstract}
Stream data shows a sequence of values changing continuously over time. Due to the nature of stream data, its trend is continuously changing according to various time intervals. Therefore the prediction of stream data must be carried out simultaneously with respect to multiple intervals, i.e. Continuous Multiple Prediction(CMP). In this paper, we propose a Continuous Integrated Hierarchical Temporal Memory (CIHTM) network for CMP based on the Hierarchical Temporal Memory (HTM) model which is a neocortex leraning algorithm. To develop the CIHTM network, we created three kinds of new modules: Shift Vector Senor, Spatio-Temporal Classifier and Multiple Integrator. And also we developed learning and inferencing algorithm of CIHTM network.
\end{abstract}

Keywords : Stream Data, Machine Learning, Continuous Multiple Prediction, HTM

\section{1. 서 론}

스트림 데이터는 연속해서 변화하는 일련의 값들로 나타 난다[1]. Fig. 1은 전형적인 스트림 데이터의 추세 변화를 나 타내고 있다. 이러한 추세 변화는 이전의 일정 시간 간격에 발생한 데이터를 바탕으로 앞으로의 경향을 예측하는데 사용 할 수 있다. 예를 들어, 10 개의 시간 간격으로 앞의 데이터에 따라 현 시점에서 상승 또는 하강 등을 예측할 수 있다.

이러한 스트림 데이터는 기온 변화, 주식 시세 등 매우 많은 분야에서 나타난다. 따라서 그동안 스트림 데이터의 추세 예측에 대해 다양한 연구가 이루어져 왔다[2-6]. 특히 인공신경망을 이용한 예측 기법들이 많이 개발되었다. 최근 이러한 인공신경망과 유사한 HTM 기술을 이용한 스트림 데이터의 추세 예측 방법이 제안되었다[11]. HTM[4]은 두뇌 의 신피질 동작 기재를 보다 가깝게 흥내낸 신피질 학습 모 델(Neocortex Learning Model)로 그동안 주로 이미지 인식 분야에 적용되어 왔으나, 최근 스트림 데이터의 추세 예측 에도 사용될 수 있음이 확인된 것이다. 즉, HTM을 이용한 주식 가격 예측[10], 스트림 데이터의 다중-간격 예측[11], HTM 기반의 주식 가격 연속 예측[12] 등이 발표되었다. 그 러나 이러한 HTM 기반 스트림 데이터 예측 기법들은 스트 림 데이터의 다양하고 동적인 요구를 제대로 반영할 수 없 었다. 즉, 스트림 데이터의 특성상 다양한 시간 간격의 기준 에 따라 계속적으로 그 동향이 달라질 수 있다. 이 때문에

\footnotetext{
※ 본 연구는 2011년도 정부(교육과학기술부)의 재원으로 한국연구재단의 기 초연구사업 지원(No.2011-0007857)을 받아 수행된 것임.

† 정 회 원 : 경상대학교 컴퓨터과학과 석사과정

†† 정 회 원: 연암공업대학 전기컴퓨터공학과 교수

+十+ 종신회원 : 경상대학교 컴퓨터과학과 교수, 컴퓨터정보통신연구소 연구원

논문접수 : 2012 년 2월 14일

수 정 일 : 1차 2012년 7월 9 일

심사완료 : 2012년 7월 10일

* Corresponding Author: Kang Hyun-Syug(hskang@gnu.ac.kr)
}

스트림 데이터의 추세 예측은 간격이 갱신될 때 마다 연속 적인 환경에서 여러 간격들을 기준으로 동시에 이루어져야 한다. 따라서 보다 현실적인 스트림 데이터의 추세 예측을 지원하기 위해서는 연속적으로 다중 예측을 수행하는 연속 다중 예측(Continuous Multiple Prediction, $\mathrm{CMP}$ ) 기법이 필 요하다. 그러나, 지금까지 HTM을 이용한 스트림 데이터의 예측 기법들은 단일 예측, 연속 예측, 다중 예측 한가지만을 제공하는 것들로 연속 다중 예측에는 효과적이지 못하다.

본 논문은 이를 극복하기 위해 연속 예측과 다중 예측을 효과적으로 통합하는 연속 통합 $\mathrm{HTM}$ (Continuous Integrated HTM, CIHTM) 네트워크를 제시한다. 이를 위해 이동 벡터 파일 센서 노드, 시공간 분류 노드, 다중 통합 노드를 고안 한다. 그리고 이러한 노드들과 기존의 HTM 노드들을 이용 하여 CIHTM 네트워크에서 연속적으로 다중 예측이 가능한 학습과 추론 방법을 고안한다.

본 논문은 7 개의 장으로 구성된다. 2장에서는 연속 예측과 다중 예측 개념을 소개한다. 3장에서는 HTM 네트워크를 이 용한 스트림 데이터의 기존 예측 방법들이 갖는 문제점을 알 아본다. 4장에서는 이를 극복하기 위해 개발한 세가지 새로 운 노드 타입들을 기술하고, 5장에서는 연속 다중 예측 기법 을 제안한다. 6 장에서는 이를 기존 기법들과 비교 분석한다. 마지막으로 7장에서는 결론과 향후 과제를 논한다.

\section{2. 연속 다중 예측}

여기서는 연속 다중 예측 $(\mathrm{CMP})$ 의 두 개념인 연속 예측 과 다중 예측을 알아 본다

\section{1 연속 예측}

연속 예측(Continuous Prediction, $\mathrm{CP}$ )은 스트림 데이터의 추세를 단위 시간의 연속적인 변화에 따라 예측하는 것을 


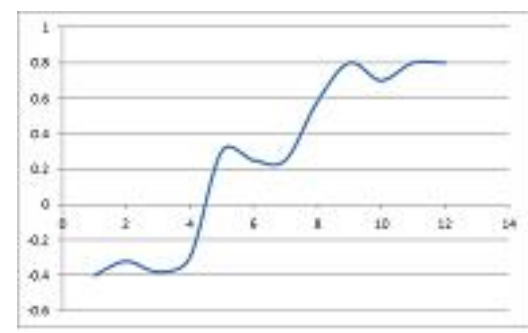

(가) 상승

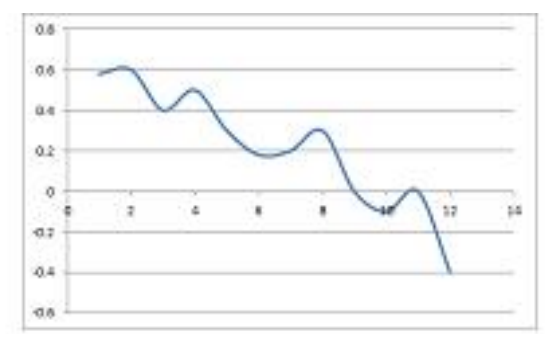

(나) 하강

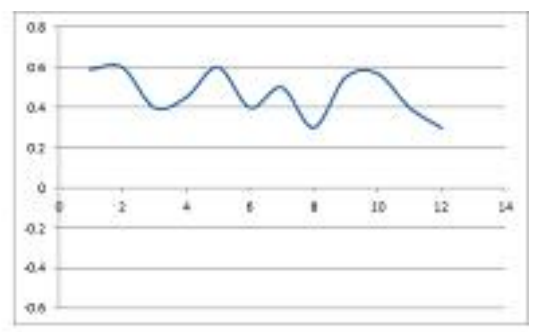

(다) 안정

Fig. 1. Tendency Prediction of Stream Data

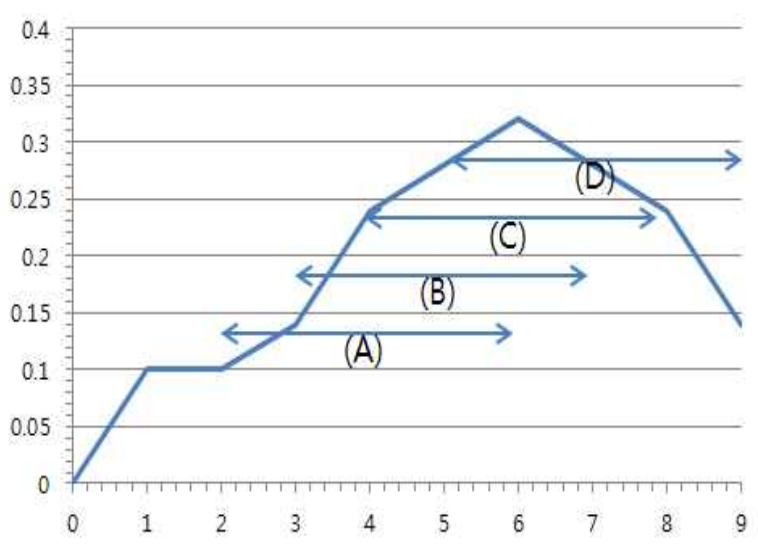

Fig. 2. General of Continuous Prediction

말한다. Fig. 2는 스트림 데이터의 연속 예측을 나타낸 것으 로 그래프에서 $x$ 축은 시간을 $y$ 축은 값을 나타낸다. 화살표 는 관측하고자 하는 시간 간격을 나타내며 시간의 흐름에 따라 설정된 간격에서 추세 변화를 보인다. 여기서는 5 분 간격의 시간 구간이 1 분 단위로 추세가 변화하는 모습을 나 타낸다. 그림의 (A) 와 (B) 구간에서는 계속 상승하는 경향 을 보이고 있고, 또한, $(\mathrm{C})$ 구간에서는 상승에서 하강으로 변하고 있으며, (D) 구간에서는 하강하는 모습을 보이고 있 다. 이처럼 시간이 흐르면서 추세 예측이 계속 달라질 수 있기 때문에 예측은 연속적으로 값이 갱신될 때마다 이루어 져야 한다.

\section{2 다중 예측}

다중 예측(Multiple Prediction, MP)은 여러 개의 구간들 을 기준으로 동시에 추세를 예측하는 것을 말한다. Fig. 3은 같은 스트림 데이터에 대해 어느 특정 시점에서 현재 값에 대해 1 분, 4 분, 12 분 간격들을 선택하여 세 개의 다른 예측 결과들이 동시에 제공될 수 있다는 것을 보인다. 전체적으 로 12 분 간격을 기초로 했을 때 경향은 하강 국면을 나타내 지만, 현재보다 1 분 전까지의 간격을 기초로 한 경향은 상 승 국면, 현재에서 앞의 4 분 동안의 간격을 기초로 한 경향 은 변동 국면을 나타내고 있다. 이처럼 같은 데이터에 대해 같은 시점임에도 불구하고 기준 구간에 따라 다른 예측 결 과들이 나타날 수 있다.

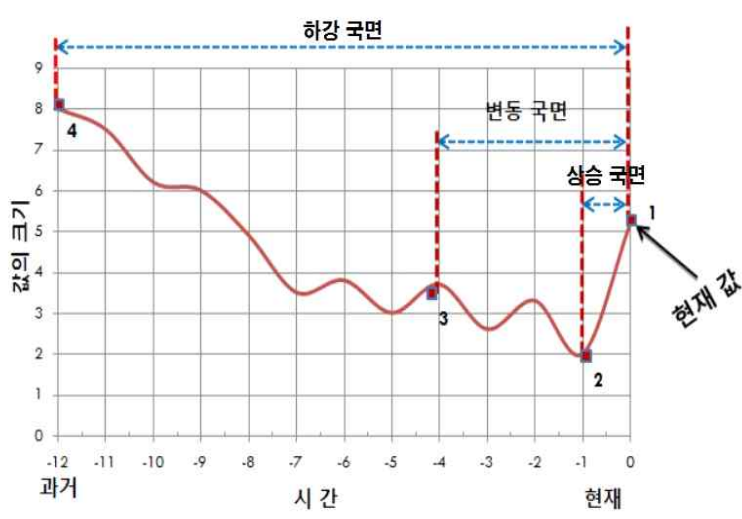

Fig. 3. Section Prediction Result of Tendency

\section{HTM 기반 스트림 데이터 예측의 문제점}

$\mathrm{HTM}$ 은 신피질 학습 모델로 신피질의 구조와 그 기능적 특성을 반영하고 있다. 이는 노드들을 트리 모양으로 구성 하고 있으며, 각 노드는 공통적인 학습과 메모리 기능을 가 지고 있는 신피질 컬럼에 해당한다[7]. 전형적인 HTM 네트 워크의 경우, 낮은 계층에서는 통제되지 않은(unsupervised) 학습을 하기 위하여 공간적 풀러 노드(Spatial Pooler Node) 와 시간적 풀러 노드(Temporal Pooler Node)들이 사용된다. 그리고 네트워크의 맨 위 계층에서는 카테고리 센서 (Category Sensor)로부터 카테고리 정보를 제공받아 배타적 으로 통제된(supervised) 학습을 하기 위하여 분류기 노드 (Classifier Node)가 사용된다[9].

이러한 HTM 기술을 스트림 데이터의 추세 예측에 적용 하기 위해서는 우선 적합한 HTM 네트워크를 구성해야 한 다. 이 장에서는 이 HTM 기술을 스트림 데이터의 추세 예 측에 사용하기 위한 HTM 네트워크 구조를 알아보고, 연속 다중 예측을 지원하기 위한 기존 방법의 문제점을 밝힌다.

\section{$3.1 \mathrm{HTM}$ 을 이용한 스트림 데이터의 추세 예측 방법}

일반적으로 하나의 HTM 네트워크는 일정 간격을 기초 로 하는 하나의 예측 결과를 생성할 수 있다[10]. Fig. 4는 세 계층으로 이루어진 HTM 네트워크가 60분간을 기초로 해 스트립 데이터의 경향을 예측하는 것을 보여준다. 입력 


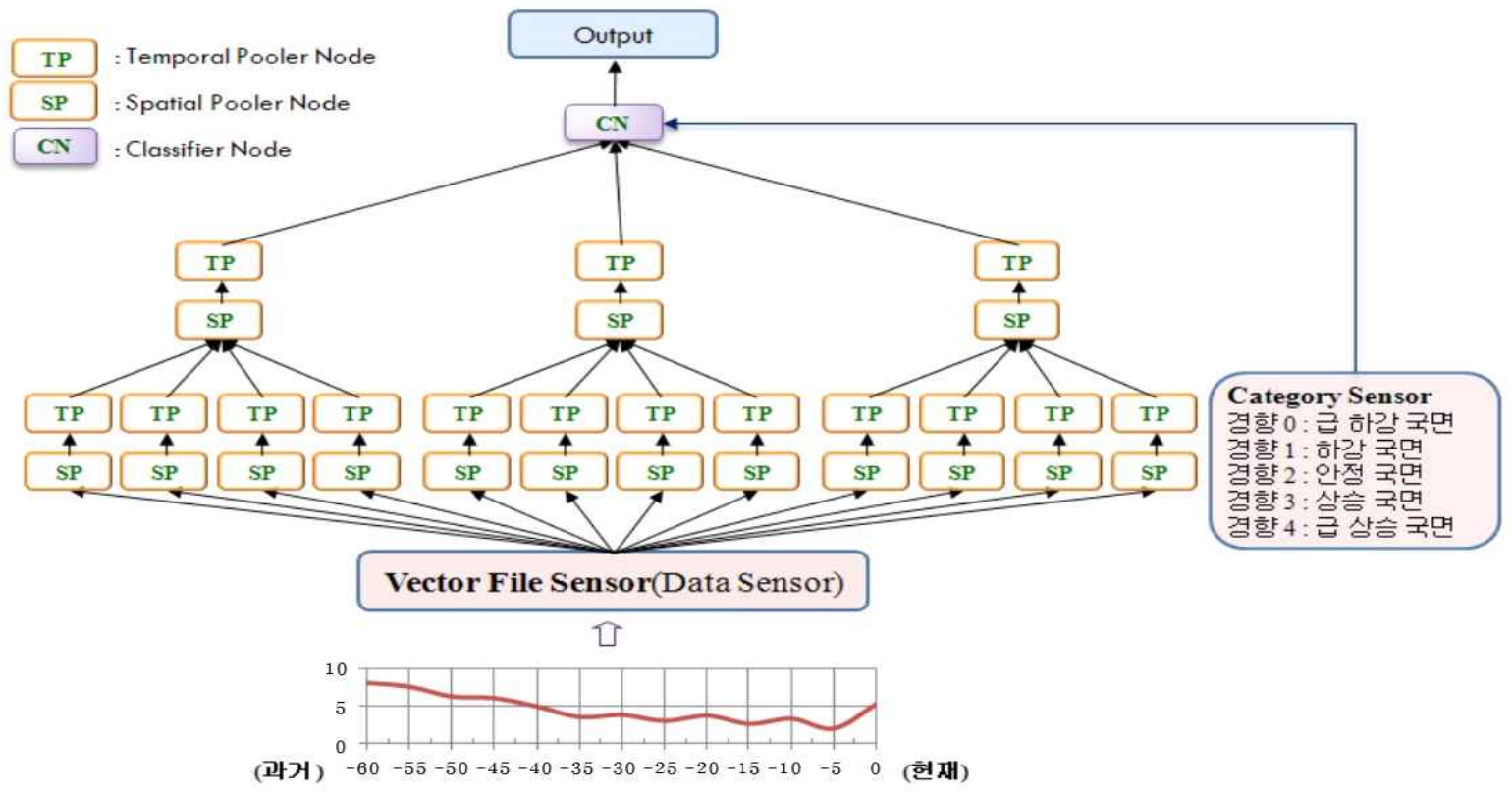

Fig. 4. Structure of HTM Network

은 1 분이 기본 단위로 이루어진 60 분 간격의 값들이다. 바 닥 계층의 각 공간적 풀러 노드는 센서로부터 5 분 간격의 데이터에 해당하는 입력을 받는다. 각 공간적 풀러 노드는 공간적 풀러 알고리즘에 의하여 연산을 수행한 후 그 결과 를 바로 위의 시간적 풀러 노드로 올려준다. 그리고 계층 2 에서 공간적 풀러 노드의 입력은 각 5 분 간격에 해당하는 네 개의 자식 노드들의 결과와 결합한 것으로 20 분 간격의 데이터이다. 맨 위 계층의 분류기 노드에서는 전체 12 개의 5 분 간격들 즉, 60 분 간격 전체에 해당된다. 그리고 분류기 노드는 다섯 개의 경향 범주들 즉, 경향 0 은 급 하강 국면, 경향 1 은 하강 국면, 경향 2 는 안정 국면, 경향 3 은 상승 국 면, 경향 4 는 급상승 국면 등을 바탕으로 통제된 학습을 수 행한다.

그런데 이러한 HTM 네트워크의 구조는 학습과 추론을 통해 일정 간격의 정적인 스트림 데이터에 대한 패턴을 인 식할 수 있다.

일반적인 HTM 네트워크의 학습은 아래로부터 레벨별로 이루어진다. 학습 단계에서 공간적 풀러는 입력 패턴을 정 량화하여 이들의 동시 발생들을 찾는다. 따라서 공간적 풀 러의 출력은 동시 발생들의 목록들이고, 이 목록들을 시간 적 풀러에 보내게 된다. 시간적 풀러는 이 목록들을 받아서 시간적으로 동시에 발생되는 패턴들을 그룹으로 묶음으로써 학습을 완료하게 된다. 학습이 완료되면 위 레벨로 보낼 데 이터를 결정하기 위해 입력 데이터들에 대해 추론하는 추론 (Inference) 단계로 이행되고, 추론은 아래로부터의 입력 패 턴에 대해 학습 단계에서 학습한 동시발생에 대한 그룹들에 대한 범주의 분포를 발생시킨다. 이렇게 하여 네트워크의 모든 노드들이 학습을 완료하게 되며, 훈련이 끝난 HTM 네트워크가 완성된다[4, 12].
이를 이용하여 새로운 입력 데이터를 인식할 수 있게 되 는데, 이것은 최상위 레벨에서 추론을 하는 것을 의미한다. 최상위 레벨의 추론 결과는 입력 데이터의 패턴 범주들에 대한 확률 분포를 나타낸다. 즉, 정적인 상태에서 추세 패턴 을 인식하는 것이다. 그러나 앞에서 언급한 바와 같이 스트 림 데이터의 효과적인 예측을 위해서는 연속 예측과 다중 예측 개념이 필요하다.

\section{$3.2 \mathrm{HTM}$ 을 이용한 연속 예측의 문제점}

Fig. 4에서 HTM 네트워크는 벡터 파일 센서를 통해 1분 간격의 데이터 60 개를 입력받는다. 이렇게 입력받은 데이터 는 레벨 1 각각의 공간적 풀러 노드에 5 개씩 입력되고 추론 한 결과를 상위 레벨로 보낸다. HTM 네트워크는 이로써 60 분 간격의 스트림 데이터를 기초로 경향을 예측한다. 그 러나 이는 정적인 예측으로, 연속적으로 매 분 마다 같은 시간 간격을 기초로 예측하는 데는 사용할 수 없다. 우리는 다음 장에서 새로운 노드 타입으로 연속 입력이 가능한 이 동 벡터 파일 센서를 고안하여 이를 해결하고자 한다.

\subsection{HTM을 이용한 다중 예측의 문제점}

Fig. 4의 HTM 네트워크는 공간적 풀러 노드와 시간적 풀러 노드가 낮은 계층들에서 통제되지 않은 학습을 하게 된다. 공간적 풀러 노드의 출력은 동일한 계층의 시간적 풀 러 노드에 입력으로, 그리고 시간적 풀러 노드의 출력은 맨 위 계층의 분류기 노드에 이르기 까지 더 상위 계층의 입력 이 된다. 분류기 노드는 맨 위 계층에서 통제된 학습을 수 행하고 범주 정보를 바탕으로 예측 결과를 생성한다. 이것 은 원래의 HTM 네트워크에서 하나의 고정된 간격을 처리 하기 위하여 단 하나의 분류기 노드가 존재한다는 것을 의 


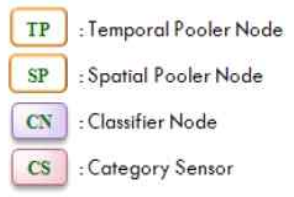

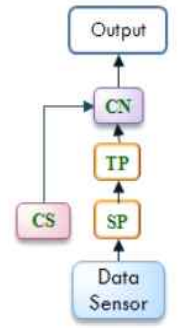

(가) 5 분 간젹의 $\mathrm{HTM}$ Network

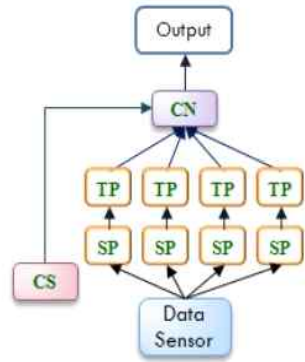

(나) 20 분 간져의 HTM Network

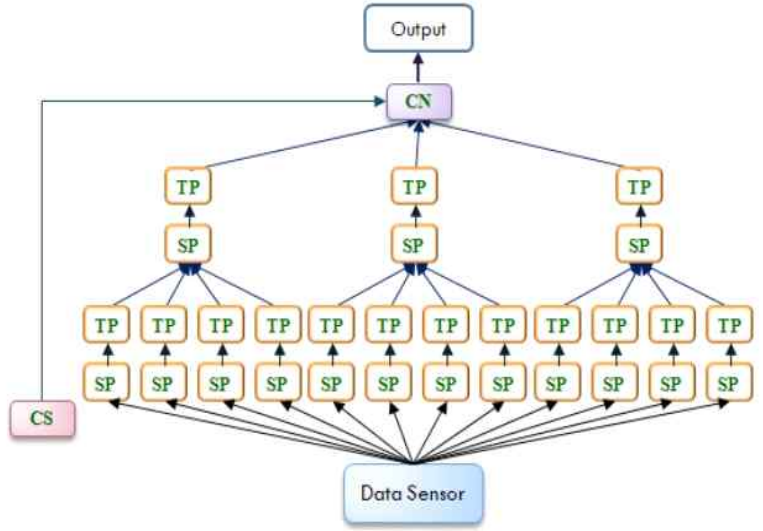

(다) 60 분 간젹의 HTM Network

Fig. 5. Multiple Prediction of Multiple HTM Network

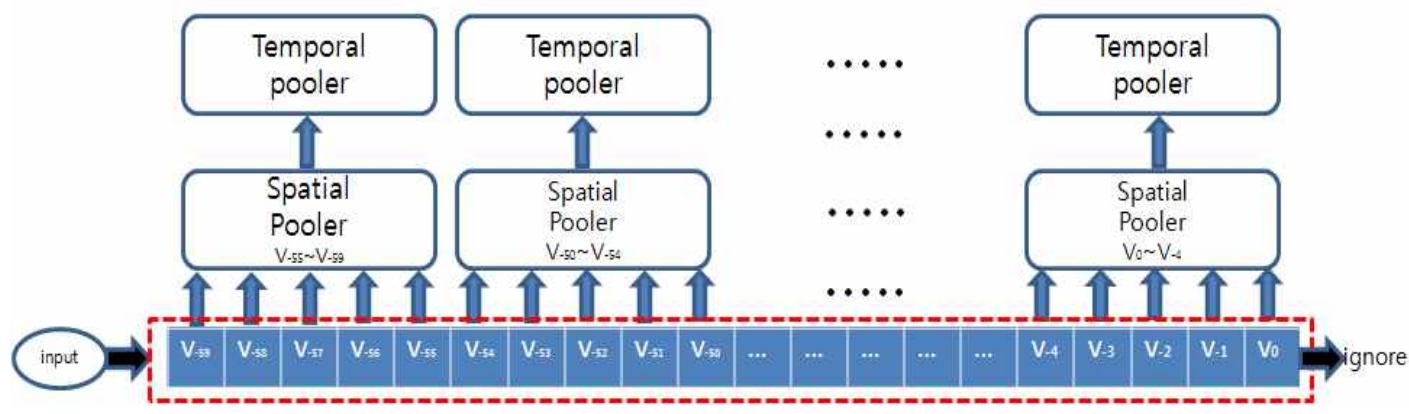

Fig. 6. Structure of Shift Vector File Sensor

미한다. 그러므로 하나의 네트워크로는 하나의 예측 결과만 얻을 수 있다. 따라서 우리가 다중 예측을 제공하기 위해서 는 서로 다른 간격을 기초로 하는 여러개의 HTM 네트워크 들을 만들어야 한다. 즉, 아래 Fig. 5에 보인 것과 같이 세 개의 예측 구간을 설정하여 예측을 할 경우에는 세 개의 네 트워크들이 필요하다.

Fig. 5의 (가)는 5분 간격의 변동을 다루며, Fig. 5의 (나) 는 20 분 간격의 값의 변동을, 그리고 Fig. 5 의 (다)는 60 분 간격의 변동을 다루게 된다. 따라서 네트워크의 수는 예측 구간의 갯수와 같으며, 각 네트워크의 크기는 예측구간의 길이에 비례한다. 결국 이러한 방법으로 다중 예측을 지원 하기 위해서는 많은 메모리와 계산 시간을 요구하게 된다. 우리는 다음 장에서 새로운 노드 타입인 시공간 분류 노드 와 다중 통합 노드를 고안하여 여러 HTM 네트워크들을 효 과적으로 통합하는 방법으로 이를 해결한다.

\section{4. 연속 다중 예측을 지원하기 위한 새로운 노드 타입들}

3장에서와 본 것과 같이 $\mathrm{HTM}$ 네트워크가 연속 다중 예측을 지원하기 위해서는 기존 HTM 노드 타입들 외에
새로운 노드 타입들이 필요하다. 여기서는 이를 위해 한 가지 입력 센서인 이동 벡터 파일 센서와 두 가지 노드 타입들인 시공간 분류 노드와 다중 통합 노드를 새롭게 제안한다.

\section{1 이동 벡터 파일 센서}

$\mathrm{IHTM}[12]$ 의 스트림 센서는 1 개의 노드만을 가지고 학 습된 데이터와 비교하는 추세 예측 기법이다. 이에 비해 여기서는 연속 입력이 가능한 이동 벡터 파일(Shifted Vector File, SVF) 센서를 제안하는데 연속적으로 입력되 는 스트림 데이터를 자리 이동된 벡터 형태로 1 개 이상을 계속해서 생성하여 HTM 네트워크의 입력으로 보내는 센 서이다. 이동 벡터 파일 센서는 스트림 데이터를 입력받아 버퍼에 누적하며 HTM 네트워크의 바닥 레벨에 있는 공 간적 풀러 노드들에 입력으로 보낸다. 예를 들어, Fig. 6은 60 개의 데이터를 가지는 이동 벡터 파일 센서로서 다섯 개의 값들을 묶어 레벨 1 의 각 공간적 풀러 노드의 입력 값으로 동시에 보낸다. 즉, 외부에서 $\mathrm{V}_{-59}$ 로 입력되면 기존 $\mathrm{V} 0$ 에서 $\mathrm{V}_{-58}$ 까지의 값들은 동시에 한칸씩 오른쪽으로 이 동되며 $\mathrm{V} 0$ 는 무시되고 5 개의 값들이 짝이 되어 해당 공간 적 풀러에 동시에 입력된다. 


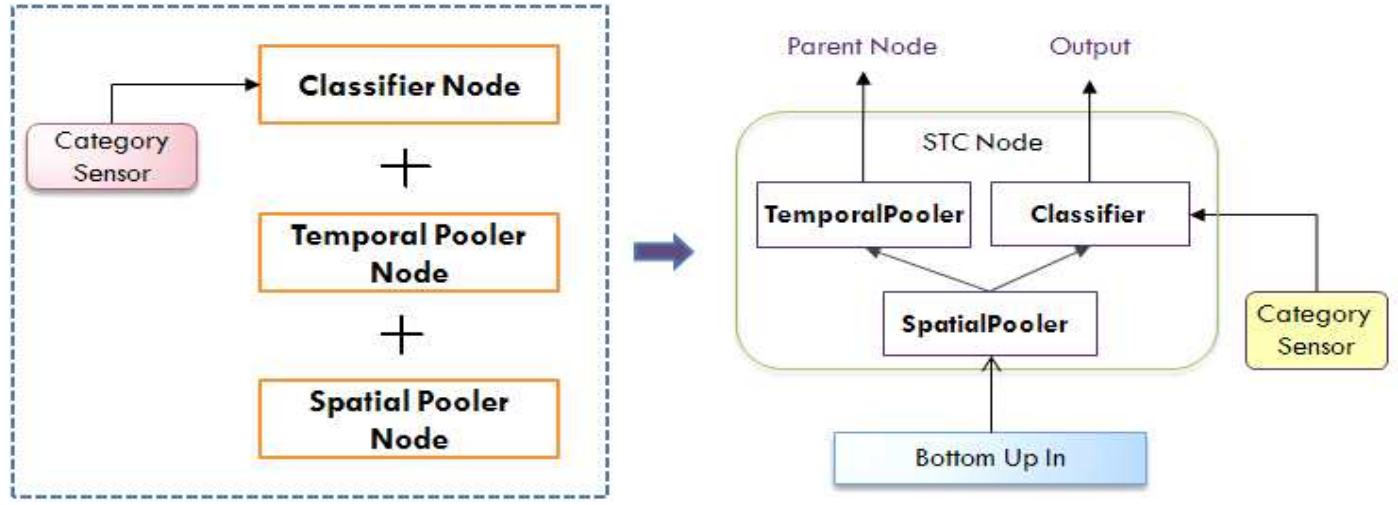

Fig. 7. Structure of Spatial Temporal Classified Node

\section{2 시공간 분류 노드}

시공간 분류 노드(Spatial Temporal Classified Node, STC Node)는 공간적 풀러와 시간적 풀러, 그리고 분류기의 결합으로 구성됨을 Fig. 7에서 알 수 있다. 공간적 풀러, 시 간적 풀러, 그리고 분류기는 원래의 HTM 네트워크가 갖는 세 기본 노드 타입들인 공간적 풀러 노드, 시간적 풀러 노 드, 분류기 노드와 기능 및 구조가 거의 동일하다. 공간적 풀러는 데이터의 공간적 패턴을 분류하는 역할을 수행하고, 시간적 풀러는 데이터의 동시발생(Coincidence)을 기초로 시 간적 패턴을 그룹화 하는 알고리즘을 수행하며, 분류 노드 는 추론 연산 모드를 수행한다. HTM 네트워크에서 해당 노드들은 개별적으로 수행을 하지만 시공간 분류 노드는 공 간적 풀러 노드, 시간적 풀러 노드, 분류기 노드를 통합한 것으로 통제된 학습과 통제되지 않은 학습 모두를 지원한 다. 시공간 분류 노드는 시간적 풀러 노드 등과 같이 학습 과 추론 연산 모드를 갖는다.

학습 모드에서 시공간 분류 노드의 공간적 풀러는 입력된 값을 양자화를 통해 표현 가능한 정규 입력 집단으로 변환 시킨다. 그리고 이들 정규 입력들을 공간적 관점에서 분류 하여 동시발생(coincidence) 행렬을 생성하게 한다. 그리고 공간적 풀러의 출력은 동시발생의 색인들로서 시간적 풀러 와 분류기에 동시에 보내진다. 시간적 풀러는 동시발생의 색인들을 받아서 시간적으로 가장 가까운 시간에 발생하는 동시발생들의 그룹들을 생성한다. 이때 각 그룹은 학습 동 안에 서로 함께 자주 발생한 동시발생들이 모여 있게 된다. 반면, 분류기는 동시발생의 색인들을 받아서 카테고리 센서 로부터 받은 범주들에 사상시켜 출력한다. 이로써 학습이 모두 끝나게 된다. 그리고 추론 모드에서 시공간 분류 노드 의 공간적 풀러는 새로운 입력 데이터의 믿음 벡터(belief vector)를 생산하기 위하여 동시발생들과 비교한다. 공간적 풀러의 출력은 학습된 모든 동시발생들의 분포이다. 이 출 력은 동시에 시간적 풀러와 분류기에 보내진다. 시간적 풀 러는 이들 그룹들의 전반적인 분포를 믿음 벡터로 변환한 다. 이 믿음 벡터들은 더 높은 계층의 입력이 된다. 그리고 분류기는 공간적 풀러로부터 믿음 벡터를 받아서 범주들의 분포를 생성하게 된다.

\section{3 다중 통합 노드}

다중 통합 노드(Multiple Integration Node, MI Node)는 추론 결과의 가중치를 고려하여 통합해 하나의 예측 결과 값을 만들어 내는 노드이다.

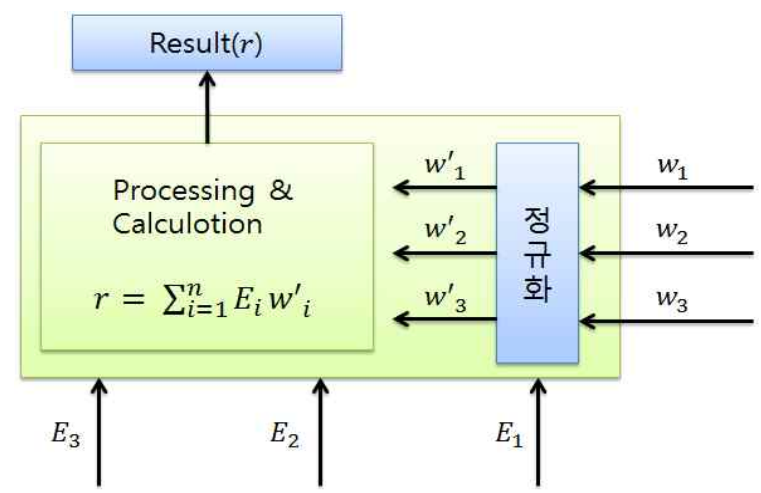

Fig. 8. Structure of Multiple Integration Node

Fig. 8에서 다중 통합 노드는 각 네트워크의 추론 결 과들인 $E_{1}, E_{2}, E_{3}$ 을 받고, 외부사용자로부터 가중치 $w_{1}, w_{2}, w_{3}$ 을 전달 받아서 연산을 하게 된다. 이때 가중치 의 기본(default) 값은 1 이며, 사용자의 요구 성향에 따라 1 에서 5 의 자연수를 설정하게 된다. 예를 들어 사용자가 단기 예측에 관심이 많을 경우는 예측 시간 간격이 짧은 $w_{1}$ 에 가중치를 높게 설정하고, 장기 예측에 관심이 많을 경우는 예측 시간 간격이 상대적으로 긴 $w_{3}$ 에 가중치를 높게 설정한다. 이러한 가중치는 효과적인 처리를 위해 우선 정규화 과정을 거치게 된다. 정규화는 추론 결과를 입력된 가중치의 비율로 재계산하는 것이다. 이렇게 정규 화를 거친 값 $w_{i}^{\prime}$ 의 총합은 추론 결과의 갯수 $\mathrm{n}$ 과 같다. 최종적인 판단은 결과값 $r$ 에 의하여 결정되는데, 이는 가 중치의 정규화 값들과 추론 결과 값들의 곱들의 합이 된 다. 그리고 결과값의 최대값과 최소값은 범주의 수 $c$ 에 따라 결정된다. 여기서 범주의 수 $\mathrm{c}$ 를 미리 결정해 놓을 수 있는데, $\mathrm{c}$ 의 값이 클수록 범주의 수가 많아져 다양한 
판단이 가능한 반면 처리 시간이 더 걸린다. 예를 들어 $\mathrm{c}$ 의 값을 5 로 가정하면 1 에서 5 의 범주의 수에 의해 결 과값의 최대값과 최소값을 확인할 수가 있다. 즉, 가중치 의 기준에서 기준치보다 높다고 한다면 상승 국면을 기준 치보다 낮다고 한다면 하강 국면을 보여주게 된다. 또한, 최대값의 수식은 $r_{\max }=\frac{(c-1)}{2} \times n$ 이고, 최소값의 수 식은 $r_{\mathrm{min}}=-\frac{(c-1)}{2} \times n$ 이 되며, 계산된 결과값 $r$ 이 $r_{\max }$ 에 가까울수록 상승 경향이 강함을 의미하며, $r_{\min }$ 에 가까울수록 하락하는 경향이 강함을 의미한다. 이들을 수식 으로 표현하면 식 (1)-(4)로 나타낼 수 있다.

$$
\begin{gathered}
w_{i}^{\prime}=\frac{n}{\sum_{i=1}^{n} w_{i}} \times w_{i} \\
n=\sum_{i=1}^{n} w_{i}^{\prime} \\
r=\sum_{i=1}^{n} E_{i} w_{i}^{\prime} \\
-\frac{(c-1)}{2} \times n \leq r \leq \frac{(c-1)}{2} \times n
\end{gathered}
$$

예를 들어 추론 결과들 $\left(E_{1}, E_{2}, E_{3}\right)$ 의 수 $\mathrm{n}$ 이 3 , 범주의 수 $c$ 가 5 , 추론 결과 값이 각각 $E_{1}=2, E_{2}=0$, $E_{3}=1$ 이며, 입력된 가중치가 각각 $w_{1}=3, w_{2}=1$, $w_{3}=1$ 이라고 할 때, 결과 $r$ 의 계산을 위해 먼저 가중치 들을 정규화하면 $\quad w_{1}^{\prime}=\frac{3}{5} \times 3=\frac{9}{5}, \quad w_{2}^{\prime}=\frac{3}{5} \times 1$ $=\frac{3}{5}, \quad w_{3}^{\prime}=\frac{3}{5} \times 1=\frac{3}{5}$ 가 되며, 이들을 모두 합하면 3 이 된다. 그러면 결과값 $\mathrm{r}$ 을 구하게 된다면 $r=\sum_{i=1}^{3} E_{i} w_{i}^{\prime}=2 \times \frac{9}{5}+0 \times \frac{3}{5}+1 \times \frac{3}{5}=\frac{21}{5}$ 이 된다. 그런데 $\frac{21}{5}$ 은 4.2 이므로 결과값의 최대값 $\left(r_{\max }\right)$ 의 계산된 값 6 에 근접하므로 자신이 지정한 가중치의 기준에 따라 현재 스트림의 값이 상승 국면에 있다는 것을 알 수 있다.

\section{5. 연속 다중 예측을 위한 CIHTM 네트워크}

여기서는 연속 다중 예측(CMP)을 위해 여러 HTM 네트 워크들을 효과적으로 통합해 하나로 운영할 수 있는 연속
통합 HTM 네트워크(CIHTM)의 구조를 제안하고, 이에 바 탕한 학습과 추론 방식을 제안한다.

\section{1 $\mathrm{CH}$ TMM 네트워크의 구조}

앞에서 언급한 바와 같이 CIHTM 네트워크는 연속 다중 예측(CMP)이 하나의 네트워크로 가능하도록 구성하여야 한 다. 이를 위해서 CIHTM 네트워크를 구성하는데, 기본 $\mathrm{HTM}$ 센서와 노드 타입들 외에도 4장에서 새롭게 개발된 센서와 노드 타입들을 이용한다. 즉, 연속 예측을 위해 이동 벡터 파일 센서를 사용하고 다중 예측을 위해 시공간 분류 노드와 다중 통합 노드를 사용한다. Fig. 9는 CIHTM 네트 워크의 구조이다. 우리는 Fig. 5에서 본 3개의 HTM 네트워 크가 하나의 네트워크로 통합된 것을 볼 수 있다.

\section{$5.2 \mathrm{ClHTM}$ 네트워크의 동작}

$\mathrm{CIHTM}$ 네트워크는 두 단계로 동작된다. 학습과 추론이다.

\section{1) 학습 단계}

CIHTM 네트워크는 원래의 HTM 네트워크와 동일하게 계층 별 학습을 수행한다. 학습을 빠르게 수행하기 위하여 우리는 각 계층에서 단 하나의 시공간 분류 노드를 사용하 여 통제된 학습을 수행하게 하였다. 학습이 끝난 시공간 분 류 노드내의 공간적 풀러 노드와 시간적 풀러 노드의 데이 터 구조들과 내용은 같은 계층의 다른 노드들에 각각 복사 된다. Fig. 9를 이용하여 CIHTM 네트워크의 학습 과정을 알아본다.

학습의 첫 단계는 Fig. 9의 (1)에 나타낸 계층 1에서 단 하나의 시공간 분류 노드가 활성화되어 학습 모드로 전환된 다. 이는 계속해서 5 분 간격의 학습 데이터를 벡터 파일 센 서(참고로 학습 단계에서는 벡터파일 센서가 사용된다)로부 터 직접 받는다. 이 입력은 공간적 풀러로 바로 가게 된다. 공간적 풀러는 이 입력들의 동시발생들을 찾는다. 결국 공 간적 풀러의 출력은 동시발생들의 목록들이고, 이것들은 시 간적 풀러와 분류기에 동시에 보내진다. 시간적 풀러는 목 록들을 받아서 시간적으로 인접한 동시발생들을 같은 그룹 으로 분류한다. 반면에, 분류기는 동시발생 목록들을 범주들 에 사상시킨다. 여기서 모든 학습이 끝난 후 시공간 분류 노드의 공간적 풀러와 시간적 풀러의 구조들은 같은 계층의 공간적 풀러 노드와 시간적 풀러 노드들에 복사된다.

Fig. 9의 (2)에 보인 학습의 두 번째 단계에서는 계층 2에 서 하나의 시공간 분류 노드가 그것의 계층 1 의 자식들과 같이 활성화된다. 계층 2 에서의 시공간 분류 노드는 학습 모드에 놓이게 된다. 그리고 그것의 계층 1 의 자식 노드들 은 추론 모드에 놓인다. Fig. 9의 (2)에서 네 개의 자식 노드 들은 계층 1 의 이동 벡터 파일 센서로부터 각각 추론 데이 터를 입력받는다. 그러면 이들 네 개의 자식 노드들의 출력 은 결합되어 계층 2 의 시공간 분류 노드의 입력이 된다. 계 층 2 의 시공간 분류 노드는 이 네 개의 자식 노드들로부터 20 분 간격의 데이터를 입력 받아서 계층 1 의 시공간 분류 노드에서 했었던 것과 같은 방식으로 학습을 수행한다. 


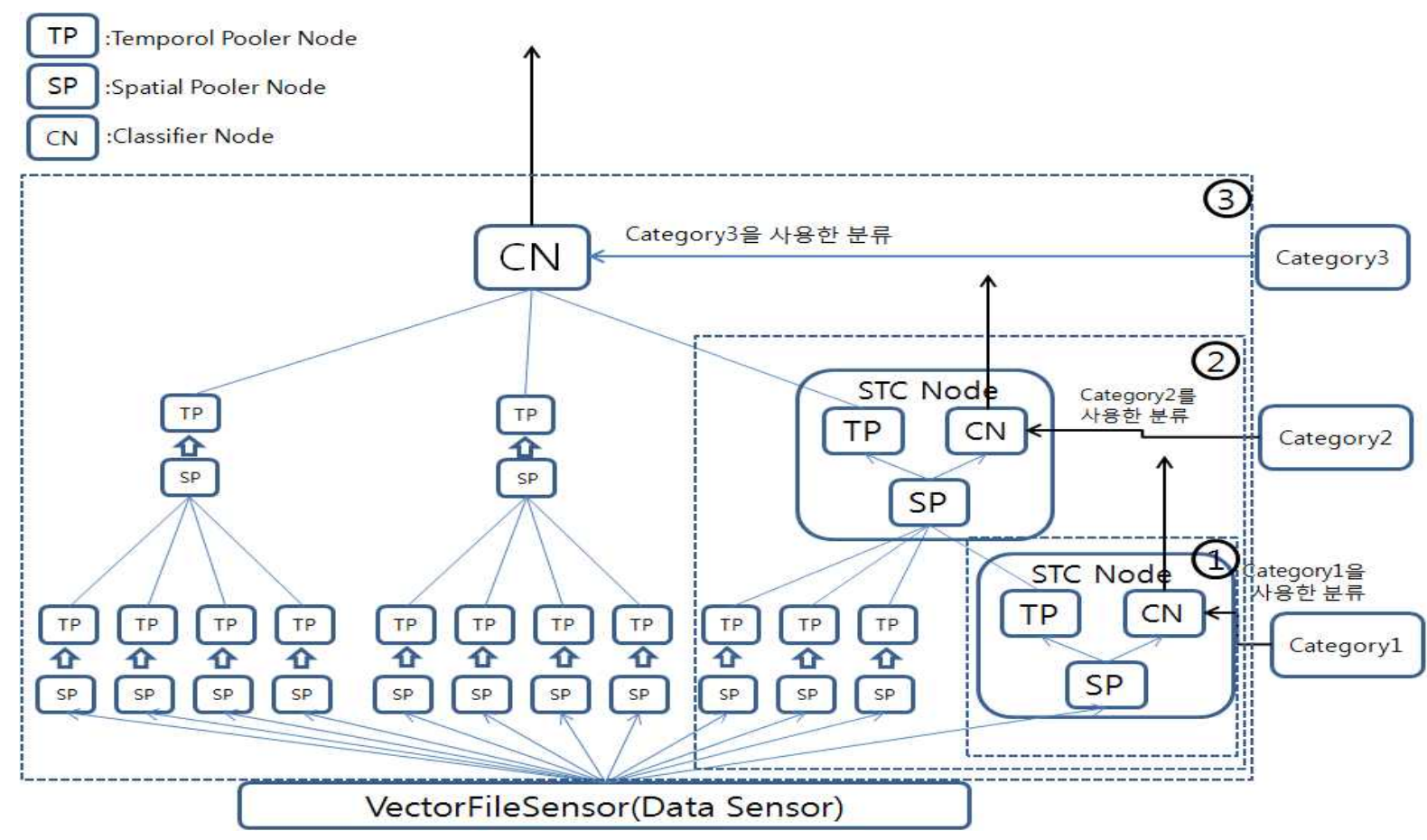

Fig. 9. Learning of ClHTM Network

계층 2 의 시공간 분류 노드가 모든 데이터에 대하여 학습 을 완료한 후에 이 노드는 추론 모드로 전환되고, 위에서 언급한 것처럼 계층 2 의 나머지 공간적 풀러 노드들과 시간 적 풀러 노드들에 데이터 구조를 복사한다. 이 과정은 네트 워크를 구성하는 모든 노드들이 활성화 될 때까지 계층적으 로 위로 올라가며 반복된다. 결국 Fig. 9의 (3)에 보인 맨 위 계층의 카테고리 센서가 학습 모드에 놓인다. 그리고 이것 의 계층 2 에 있는 3 개의 자식 노드들과 계층 1 에 있는 12 개 의 손자 노드들은 모두 추론 모드에 놓이게 된다. 이제 계 층 1 의 추론 결과 출력은 계층 2 의 노드들에 보내진다. 그 리고 계층 2 의 노드들이 수행한 추론 결과 출력들은 학습 데이터로 범주 센서에 보내진다. 이로써 CIHTM 네트워크 는 60 분 간격의 전체 스트림 데이터들을 사용하여 훈련을 완료하게 되었다.

\section{2) 추론 단계}

추론 단계 동안에는 각 계층의 모든 노드들이 활성화되고 CIHTM 네트워크는 60분 간격의 새로운 스트림 데이터에 노출된다. 추론 단계의 마지막에는 계층 1,2 에서의 시공간 분류 노드, 맨 위 계층의 카테고리 센서 노드에 의하여 5 분, 20 분, 60 분 간격을 기초로 한 추론 결과들이 각각 생성된다. 그림 10은 연속 다중 예측을 위해 CIHTM 네트워크에서 스 트림 데이터에 대해 일어나는 추론 결과를 보여준다. 추론 단계에서는 기본적인 벡터 파일 센서 대신에 이동 벡터 라 인 센서로 대체하며, 추론 결과를 최종 통합하기 위해 최상 위에서 다중 통합 노드가 사용된다.

Fig. 10에서 보는 바와 같이 바닥 계층(계층 1)의 시공간
분류 노드의 공간적 풀러와 나머지 11 개의 공간적 풀러 노 드는 결국 매 단위 시간마다 60 분 간격의 순차적인 벡터 $\left[v_{-59}, v_{-58}, \ldots, v_{-2}, v_{-1}, v_{-0}\right]$ 를 이동 벡터 파일 센서 로부터 입력받는다. $v_{i}$ 는 입력되는 스트림 값의 특정 시간 간격 동안에 발생하는 차이 값을 말하며, $t_{i}$ 는 시간 스트림 을 말한다. 즉, 여기서 입력 데이터 $t_{i}$ 의 $v_{i}$ 는 $t_{i-1}$ 에서 $t_{i}$ 까지 값의 차이이다. 예를 들면, $t_{i-1}$ 의 값 801이고 $t_{i}$ 의 값 은 812이면, $t_{i-1}$ 에서 $t_{i}$ 까지 간격 $i_{(i-1) \sim i}$ 의 값 $v_{i}$ 는 +11 이다. 계층 1 의 각 시공간 분류 노드의 공간적 풀러는 그것이 다루는 시간 간격 5 분에 상응하는 입력 즉, $i_{0-4}$ 를 받는다. 이 입력 벡터를 각 시공간 분류 노드는 학습한 동 시발생과 비교하고, 이 입력 벡터를 위한 믿음 벡터를 계산 한다. 이 믿음 벡터는 시간적 풀러에 보내진다. 시간적 풀러 는 이 믿음 벡터를 받아서 $P_{(i-4) \sim i}$ 라고 표시한 그룹 $i_{(i-4) \sim i}$ 의 믿음 분포(belief distribution)를 생성한다. 여기 서 $P_{i}$ 는 그 시점에 추론한 결과값을 말한다. 이 $P_{(i-4) \sim i}$ 는 시간적 풀러의 출력으로 공간적 그룹의 수와 같은 크기 를 갖는다. 예를 들어, 공간적 풀러 내에 10 개의 동시발생들 을 갖는 노드가 있고 이로부터 입력을 받는 시간적 풀러 내 에 4 개의 공간적 그룹을 갖는다고 가정하자. 그리고 만약 현재 입력이 시간적 그룹 2에 속한 네 번째 동시발생에 대 응된다면 시간적 풀러의 출력인 $P_{(i-4)} \sim i$ 는 4 개의 그룹들 내의 벡터들 중에서 그룹 2에 대응하는 1이 일치하여 [0100] 로 표현된다. 그리고 시공간 분류 노드의 분류기는 공간적 풀러로부터 이 믿음 벡터를 받아서 계층 1 의 5 분 간격의 예 


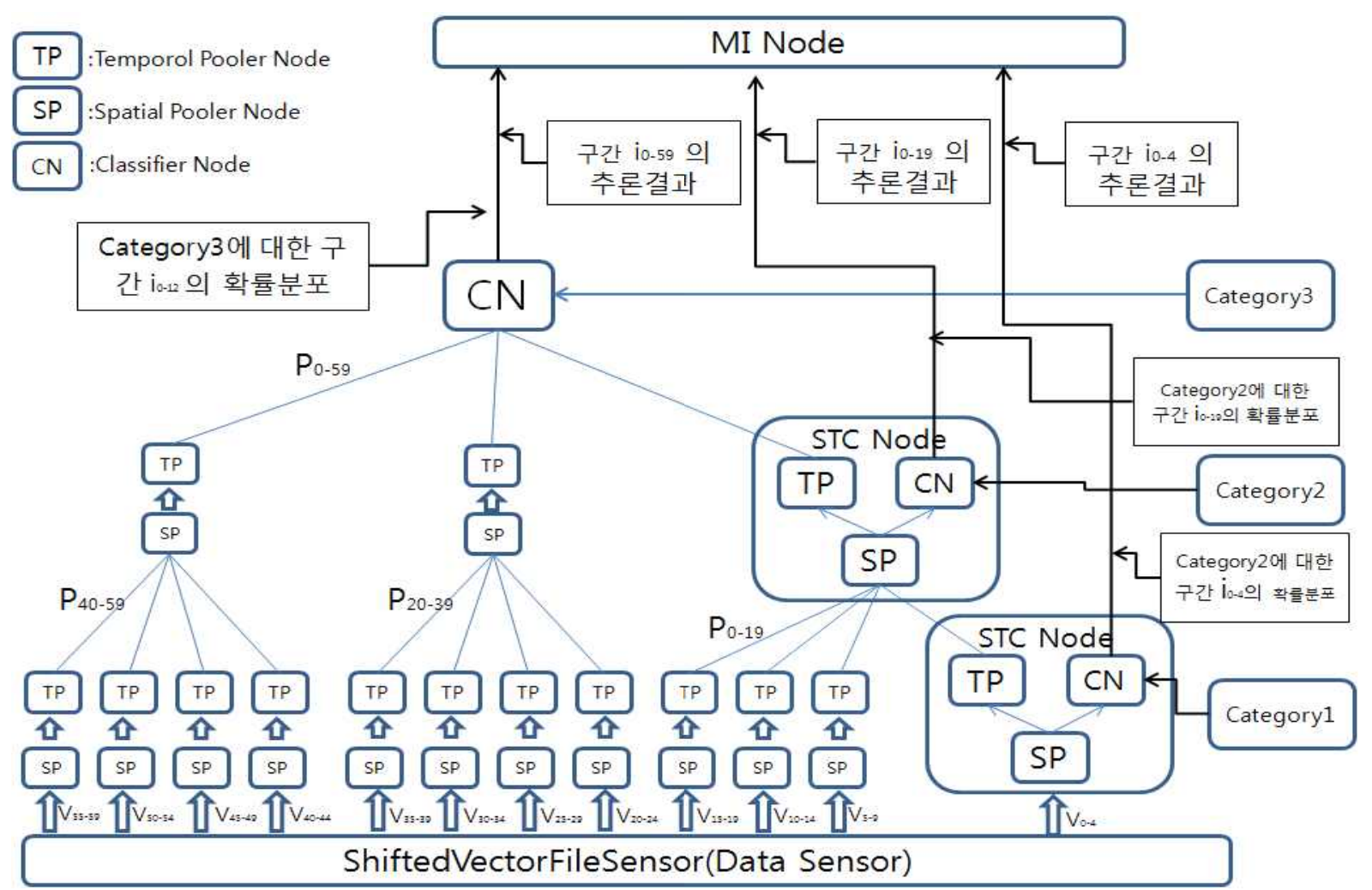

Fig. 10. Ratiocination of CIHTM Network

Table 1. Compare of HTM, IHTM, CHTM, CIHTM

\begin{tabular}{|c|c|c|c|c|}
\hline Technique & HTM[10] & IHTM[11] & CHTM[12] & CIHTM[Proposition] \\
\hline Prediction Description & 0 & 0 & 0 & 0 \\
\hline Base Prediction & $\times$ & $\times$ & 0 & 0 \\
\hline Continuous Prediction & $\times$ & 0 & $\times$ & 0 \\
\hline Integration Prediction & &
\end{tabular}

측 결과로 범주들의 분포를 생성한다. 계층 2 의 시공간 분 류 노드는 세 개의 시간적 풀러 노드와 한 개의 시공간 분 류 노드인 네 개의 자식 노드들로부터 입력을 받는다. 이 입력은 간격 $i_{0 \sim 19}$ 의 데이터 패턴이다. 시간적 풀러는 이 것의 결과인 $P_{0 \sim 19}$ 를 생성한다. 이 출력은 맨 위 계층의 카테고리 센서 노드로 올려질 패턴 정보 $P_{0 \sim 59}$ 를 위하여 다른 형제의 시간적 풀러 노드들과 연결된다. 이 노드의 분 류기는 계층 2 의 20 분 간격 $i_{0 \sim 19}$ 의 예측 결과인 범주의 분포를 생성한다. 계층 3 의 카테고리 센서 노드는 세 개의 자식 즉, 계층 2 의 하나의 시공간 분류 노드, 3 개의 시간적 풀러 노드들로부터 간격 $i_{0 \sim 59}$ 의 입력 데이터의 패턴 정보 를 받아서 60 분 간격의 예측 결과를 생성한다. 그리고 이러 한 3 개의 동시 예측 결과들은 동시에 다중 통합 노드로 보 내져 통합 연산된 후 하나의 예측 값이 최종 출력된다.

\section{6. 비교 분석}

현재까지 HTM 기술을 이용하여 스트림 데이터의 추세 예측을 시도한 경우는 HTM[10], IHTM[11], CHTM[12] 등 이 있다. 이들은 모두 한가지 기능을 중심으로 스트림 데이 터의 추세 예측을 HTM으로 해결한 방법들이다. 하지만 여 기서는 이들 기존 방법들을 효과적으로 통합해 연속 예측을 수행하는 방법을 제시하였다. 결국 여기서 제시한 CIHTM 방법은 기존 기법들을 보다 현실적으로 사용할 수 있도록 하는 통합된 방법이다. 이들을 기능 중심으로 비교하면 Table 1과 같다.

$\mathrm{HTM}[10]$ 의 경우는 기본 예측을 지원하는 기법으로 정적 인 예측을 제공하는 기법이다. IHTM[11]의 경우는 여러 시간 간격을 동시에 예측하기는 하지만 역시 정적인 기법이 다. CHTM[12]의 경우는 시간의 흐름에 따라 연속적으로 예 
측하는 기법이다. 이들에 비해 CIHTM은 연속적으로 여러 시간 간격들을 동시에 고려하여 하나의 예측 결과를 제공함 으로써 예측의 정확성을 높여주는 기법을 제공한다.

\section{7. 결론 및 향후 과제}

스트림 데이터의 추세 예측에는 과거의 변동 추세를 바탕 으로 미래 변화를 계속 다중 간격에서 동시에 예측하는 연 속다중예측 $(\mathrm{CMP})$ 이 필요하다. 본 논문에서는 이를 위해 $\mathrm{HTM}$ 기술을 기반으로 $\mathrm{CMP}$ 에 적합한 새로운 CIHTM 네 트워크 구성 방법을 제시하였다. 우리는 이를 효과적으로 구축할 수 있도록 우선 새로운 이동 벡터 파일 센서, 시공 간 분류 노드, 다중 통합 노드를 개발하였다. 그리고 이들을 이용하는 CIHTM 네트워크의 구조를 고안하고 그것이 학습 과 추론 방법을 고안하였다.

본 기법은 연속 다중 예측 결과들을 하나로 조합함으로서 보다 신뢰성있는 예측을 할 수 있는 효과적인 방법을 제시 하였다. 이는 다중 간격의 가중치들을 다양하게 조합하는 방법을 가짐으로서 사용자의 다양한 요구에 적합하게 주문 형으로 예측 결과를 사용할 수 있게 한다. 앞으로 이 기법 을 이용해 스트림 데이터의 특성을 갖는 주식 시세, 심전도, 심박수, 음파 등의 데이터에 대한 관측 및 예측 시스템을 개발한다면 실용적인 활용이 가능할 것으로 판단된다.

\section{참 고 문 헌}

[1] I. Arel, D. Rose and T. Karrowski, "Deep Machine Learning-A New Frontier in Artificial Intelligence Research", IEEE Computational Intelligence Magazine, pp.13-18, Nov., 2010.

[2] Numenta, Numanta Home Page, http://www.numenta.com.

[3] 서대호, 배선갑, 김성진, 강현석, 배종민, "HTM 기반의 주식 가 격 연속 예측 시스템 개발, 한국멀티미디어학회 논문지, 제 14 권 제9호, pp.1152-1164, 2011. 9 .

[4] 조건화, 배선갑, 심명선, 배종민, 강현석, "데이터 스트림의 다중간격 예측을 위한 통합된 계층형 시간적 메모리 네트워크," 한국 정보과학회 논문지: 소프트웨어 및 응용, 제 37 권 제 7 호, pp. 558-567, 2010. 7.

[5] Y. Hall, R. Poplin, "Using Numenta's Hierarchical Temporal Memory to Recognize CA PTCHAs", Carnegie Mellon University, 2007. Available at http://www.pembrokeballet. com/ 10701-HTM_CAPTCHA.pdf (last accessed April 1st, 2011).

[6] B. Bobier, "Handwritten Digit Recognition using Hierarchical Temporal Memory", University of Guelph, 2007. Available at http://arts.uwaterloo.ca/ $/$ cnrglab/?q=system/files/SoftCompu ting FinalProject.pdf (last accessed April 1st, 2011).

[7] D. George and B. Jaros, "The HTM Learning Algorithms", Numenta Inc., March, 2007.
[8] D. George and B. Jaros., "Zata1 Algorithms Reference," Numenta, Inc., March, 2007

[9] J. Hawkins and D. George, "Hierarchical Temporal Memory," Numenta, Inc., March, 2007

[10] Davide Maltoni, "Pattern Recognition by Hierarchical Temporal Memory", April 13, 2011, DEIS Technical Report http://bias.csr.unibo.it/maltoni/HTM_TR_v1.0.pdf

[11] J. Han and M. Kamber, "Data Mining: Concepts and Techniques," Morgan Kaufman, 2001.

[12] K. Lee and G. Jo, "Expert system for predicting stock market timing using a candlestick chart," Expert system With Applications, 16, pp.357-364, 1999

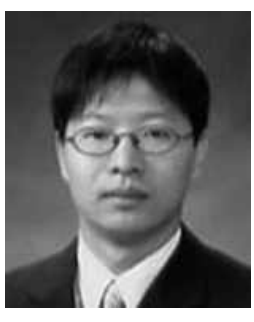

한 창 영

e-mail :wride78@gmail.com

2004년 2월 경상대학교 컴퓨터과학과 (학사)

2007년 현 재 경상대학교 컴퓨터과학과 석사과정

2004년 현 재 경상대학교 교육정보전산원 근무

관심분야: 데이터베이스, UNIX 시스템, 네트워크, WEB 등

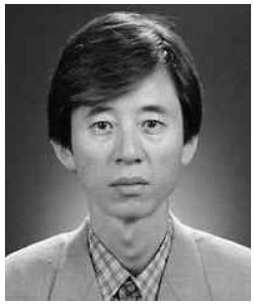

\section{김 성 진}

e-mail : sjkim@yc.ac.kr 1979년 경북대학교 전자공학과(공학사) 1981년 경북대학교 전자공학과(공학석사) 1995년 영남대학교 컴퓨터공학전공 (공학박사)

1983년 1985년 2월 삼성전자(주) 시스템개발부

1996년 1997년 University of California, Santa Cruz, 연구교수 1985년 3월 현 재 연암공업대학 전기컴퓨터공학과 교수 관심분야: 임베디드시스템, 운영체제

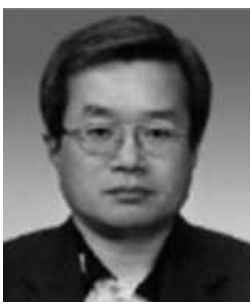

\section{강 현 석}

e-mail : hskang@gnu.ac.kr 1981년 동국대학교 전자계산학과(학사) 1983년 서울대학교 전산학과(석사) 1989년 서울대학교 전산학과(박사) 1981년 1984년 2월 한국전자통신연구원 연구원

1984년 3월 1993년 2월 전북대학교 전임강사, 부교수, 교수 1993년 3월 현 재 경상대학교 컴퓨터과학과 교수, 컴퓨터정보 통신연구소 연구원

관심분야: 멀티미디어, 내장형 데이터베이스, 지능시스템 


\section{계층형 시간적 메모리 네트워크를 기반으로 한 스트림 데이터의 연속 다중 예측}

한 창 영 $\cdot$ 김 성 진 ${ }^{++} \cdot$ 강 현 석 ${ }^{++}$

\section{요 약}

스트림 데이터는 시간에 따라 연속적으로 변화하는 일련의 값들로 나타난다. 이러한 스트림 데이터의 특성상 다양한 시간 간격의 기준에 따 라 계속적으로 그 동향이 달라질 수 있다. 이 때문에 스트림 데이터의 추세 예측은 간격이 갱신될 때 마다 연속적인 환경에서 여러 간격들을 기준으로 동시에 이루어지는 연속 다중 예측(Continuous Multiple Prediction, $\mathrm{CMP}$ )이 지원되어야 한다. 본 논문은 스트림 데이터의 연속 다중 예측을 효과적으로 지원하기 위하여, 신피질 학습 모델인 계층형 시간적 메모리(Hierarchical Temporal Memory, HTM) 모델을 확장하여 연속 통합 HTM(Continuous Integrated HTM, CIHTM) 네트워크를 제안한다. 이를 위해 우리는 HTM 네트워크를 구성하는 기존 노드들 외에 새롭 게 이동 벡터 파일 센서, 시공간 분류 노드, 다중 통합 노드를 고안하였다. 그리고 이들을 바탕으로 CIHTM 네트워크의 학습과 추론 알고리즘 을 개발하였다.

키워드 : 스트림 데이터, 기계 학습, 연속 다중 예측, HTM 